\title{
Use of a low-resistance compliant thoracic artificial lung in the pulmonary artery to pulmonary artery configuration
}

\author{
Christopher N. Scipione, MD, ${ }^{\mathrm{a}}$ Rebecca E. Schewe, MS, ${ }^{\mathrm{b}}$ Kelly L. Koch, BS, ${ }^{\mathrm{a}}$ Andrew W. Shaffer, MD, ${ }^{\mathrm{a}}$ \\ Amit Iyengar, ${ }^{b}$ and Keith E. Cook, $\mathrm{PhD}^{\mathrm{a}, \mathrm{b}}$
}

\begin{abstract}
Background: Thoracic artificial lungs have been proposed as a bridge to transplant in patients with end-stage lung disease. Systemic embolic complications can occur after thoracic artificial lung attachment in the pulmonary artery to left atrium configuration. Therefore, we evaluated the function of a compliant thoracic artificial lung attached via the proximal pulmonary artery to distal main pulmonary artery configuration.
\end{abstract}

\begin{abstract}
Methods: The compliant thoracic artificial lung was attached to 5 sheep $(63 \pm 0.9 \mathrm{~kg})$ in the proximal pulmonary artery to distal main pulmonary artery configuration. Device function and animal hemodynamics were assessed at baseline and with approximately $60 \%, 75 \%$, and $90 \%$ of cardiac output diverted to the compliant thoracic artificial lung. At each condition, dobutamine $\left(0\right.$ and $\left.5 \mu \mathrm{g} \cdot \mathrm{kg}^{-1} \cdot \mathrm{min}^{-1}\right)$ was used to simulate rest and exercise conditions.

Results: At rest, cardiac output decreased from $6.20 \pm 0.53 \mathrm{~L} / \mathrm{min}$ at baseline to $5.40 \pm 0.43,4.66 \pm 0.31$, and $4.05 \pm 0.27 \mathrm{~L} / \mathrm{min}$ with $60 \%, 75 \%$, and $90 \%$ of cardiac output to the compliant thoracic artificial lung, respectively $(P<.01$ for each flow diversion vs baseline). During exercise, cardiac output decreased from $7.85 \pm 0.70$ $\mathrm{L} / \mathrm{min}$ at baseline to $7.46 \pm 0.55,6.93 \pm 0.51$, and $5.96 \pm 0.44 \mathrm{~L} / \mathrm{min}(P=.82, P=.19$, and $P<.01$ with respect to baseline) with $60 \%, 75 \%$, and $90 \%$ of cardiac output to the compliant thoracic artificial lung, respectively. The artificial lung resistance averaged $0.46 \pm 0.02$ and did not vary significantly with blood flow rate.

Conclusions: Use of a compliant thoracic artificial lung may be feasible in the proximal pulmonary artery to distal main pulmonary artery setting if its blood flow is held at less than $75 \%$ of cardiac output. To ensure a decrease in cardiac output of less than $10 \%$, a blood flow rate less than $60 \%$ of cardiac output is advised. (J Thorac Cardiovasc Surg 2013;145:1660-6)
\end{abstract}

Lung transplantation provides the possibility of substantially increased survival for patients with end-stage pulmonary disease. Unfortunately, the demand for donor organs continues to exceed the current supply. Although changes in the donor organ allocation system have decreased waiting list mortality, there were still 266 waiting list deaths in 2008. ${ }^{1}$ To address this issue, thoracic artificial lungs (TALs) have been proposed as a bridge to lung transplantation.

Numerous case reports have shown that long-term extracorporeal membrane oxygenation (ECMO) can be used to bridge patients to lung transplantation. ${ }^{2-5}$ However, cannulation and the ECMO circuit could make pretransplant rehabilitation more difficult when compared with TAL use. ECMO is also associated with blood

From the Department of General Surgery, ${ }^{a}$ University of Michigan Medical Center, Ann Arbor, Mich; and Department of Engineering, ${ }^{b}$ University of Michigan, Ann Arbor, Mich.

Funding: National Institutes of Health, R01 HL089043.

Disclosures: Authors have nothing to disclose with regard to commercial support.

Received for publication Sept 18, 2012; revisions received Dec 4, 2012; accepted for publication Jan 11, 2013; available ahead of print Feb 11, 2013.

Address for reprints: Keith E. Cook, PhD, B570 MSRB2, 1150 W. Medical Center Dr, Ann Arbor, MI 48109-0686 (E-mail: keicook@med.umich.edu).

0022-5223/\$36.00

Copyright (c) 2013 by The American Association for Thoracic Surgery http://dx.doi.org/10.1016/j.jtcvs.2013.01.020 element activation, hemolysis, and platelet consumption, which can lead to increased transfusions, systemic inflammatory response, and organ system failure. ${ }^{6}$

Use of a paracorporeal, pumpless TAL could enhance patient mobility preoperatively, cause fewer hematologic derangements, and expedite post-transplant recovery in patients who are bridged to lung transplantation. A previous study of the BioLung TAL (MC3 Corp, Ann Arbor, Mich) in normal sheep has shown that this device is capable of providing respiratory support for a 30-day period when used in the pulmonary artery to left atrium (PA-LA) configuration. ${ }^{7}$ Moreover, these studies demonstrated stable platelet counts and no evidence of hemolysis, suggesting better biocompatibility compared with ECMO. ${ }^{7}$ There is no purposely designed TAL available clinically. However, 6 patients have been bridged to transplant using a Novalung ILA (Novalung GmbH, Hechingen, Germany) in a PA-LA configuration. ${ }^{8-10}$ The PA-LA configuration can decrease the workload of the right ventricle (RV) by providing an alternate pathway for blood flow. However, potentially catastrophic systemic embolic complications, such as stroke, could occur. ${ }^{9,10}$

An alternative configuration, the proximal PA to distal PA (PA-PA) configuration has a low risk for systemic embolic events. This approach is limited by the increased workload of the RV having to pump sequentially through the device 


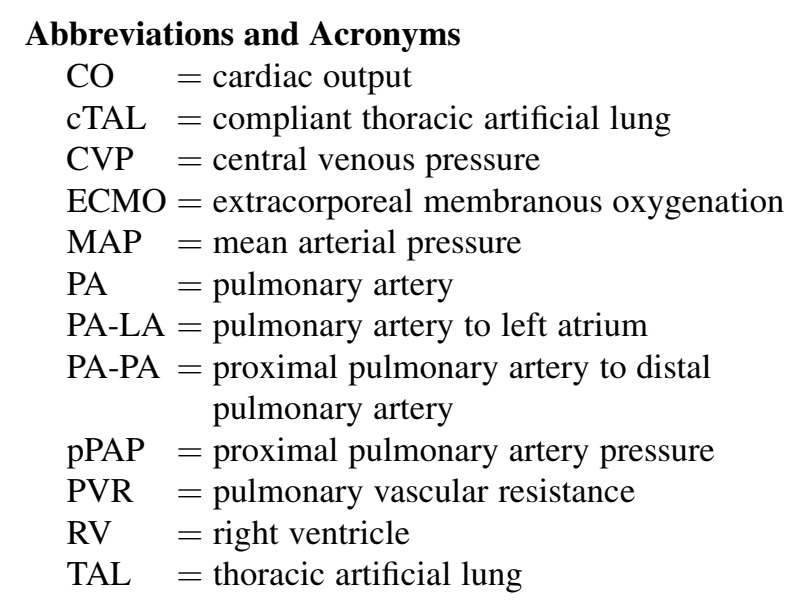

and the native lungs. Therefore, presence of pulmonary hypertension would be a relative contraindication to this attachment configuration. However, a significant subset of lung transplant candidates with chronic respiratory insufficiency do not have pulmonary hypertension (mean PA pressure $>25 \mathrm{~mm} \mathrm{Hg}$ ), including $69 \%$ of candidates with idiopathic pulmonary fibrosis, ${ }^{11} 50 \%$ with chronic obstructive pulmonary disease, ${ }^{12}$ and $37 \%$ with cystic fibrosis. ${ }^{13}$

Nonetheless, the TAL must have a stable, low resistance for this approach to be feasible. In the current study, a new compliant thoracic artificial lung (cTAL) design is examined for this setting. The cTAL uses a compliant housing with a gradual inlet in an attempt to achieve ultra-low device resistance $(0.5 \mathrm{~mm} \mathrm{Hg} /[\mathrm{L} / \mathrm{min}])$ at all relevant ranges of blood flow through the device. We hypothesized that this device with ultra-low resistance could be attached in the PA-PA configuration and maintain normal $\mathrm{CO}$ at high device flow rates. If true, this would decrease adverse events from systemic emboli in patients being bridged to lung transplantation. Thus, the current study examines the hemodynamic effect of PA-PA attachment under various percentages of $\mathrm{CO}$ diverted through the CTAL and under simulated rest and exercise conditions.

\section{MATERIALS AND METHODS \\ Compliant Thoracic Artificial Lung}

A cTAL, consisting of a compliant Biospan (DSM PTG, Berkeley, Calif) housing and polypropylene fiber bundle, was used in this study (Figure 1). This device was designed and constructed by our research group at the University of Michigan. ${ }^{14}$ In this device, blood flows into the inlet conduit, expands into the inlet manifold, flows through the fiber bundle, travels through the outlet manifold, and exits through the outlet conduit. To create the fiber bundle, woven mats of polypropylene fibers with a fiber diameter of $210 \mu \mathrm{m}$ were wound into compact bundles with porosity, path length, frontal area, and surface area of $0.75,0.038 \mathrm{~m}, 0.013 \mathrm{~m}^{2}$, and $2.4 \mathrm{~m}^{2}$, respectively.

\section{Experimental Procedure}

Five male sheep averaging $63 \pm 0.9 \mathrm{~kg}$ were used in this study. Animal numbers were based on similar previous studies. ${ }^{14}$ All sheep received humane care in compliance with the "Guide for the Care and Use of Laboratory Animals," and all methods were approved by the University of Michigan Committee for the Use and Care of Animals. Anesthesia was induced and mechanical ventilation was performed according to previous published methods. ${ }^{14} \mathrm{~A}$ carotid arterial line and left jugular venous line were placed and then connected to fluid-coupled pressure transducers (ICU Medical, Inc, San Clemente, Calif) for the continuous monitoring of mean arterial pressure (MAP) and central venous pressure (CVP).

A muscle-sparing left anterolateral thoracotomy was performed, and the fourth rib was removed. The left lung was packed laterally, and the pericardium was incised. The pulmonary artery (PA) was then identified. Dacron vascular grafts (18 mm; Terumo Medical Corp, Ann Arbor, Mich) were solvent bonded to $5 / 8$ " inner diameter polyvinyl chloride tubing (Fisher Scientific, Pittsburgh, Pa) and used as conduits for artificial lung attachment. An end-to-side anastomosis was performed between the device outlet conduit and the distal PA near the bifurcation. The device inlet end-to-side anastomosis was then performed on the proximal PA. An ultrasonic perivascular flow probe (Transonic 24AX, Transonic Systems, Inc, Ithaca, $\mathrm{NY}$ ) was placed around the PA, proximal to the device inlet graft for measurement (T400, Transonic Systems) of mean PA flow or cardiac output (CO). A pressure catheter (Becton Dickinson and Co, Franklin Lakes, $\mathrm{NJ})$ was then inserted at the proximal PA and connected to a transducer for the display and recording of the proximal PA pressure (pPAP). A Rummel tourniquet was placed around the PA between the inlet and outlet grafts to allow for the adjustment of flow through the cTAL. Pressure catheters were inserted into the distal PA near the bifurcation and into the left atrium to allow for the recording of the distal PA pressure and the left atrial pressure. Before device attachment, 1g of methylprednisolone (Solu-Medrol; Pfizer, New York, NY) was administered, and the animal was anticoagulated with $100 \mathrm{IU} / \mathrm{kg}$ of intravenous sodium heparin (Baxter Healthcare Corp, Deerfield, Ill) to maintain active clotting times greater than 300 seconds.

The cTAL was primed with heparinized saline $(10 \mathrm{U} / \mathrm{mL})$ and then connected to the proximal PA (device inlet) and distal PA (device outlet) grafts (Figure 2). An ultrasonic flow probe (Transonic 14PXL; Transonic Systems, Inc) was placed around the inflow conduit to measure (T400; Transonic Systems Inc) device flow $\left(Q_{c T A L}\right)$. The cTAL inlet and outlet pressures $\left(P_{\text {in }}\right.$ and $\left.P_{\text {out }}\right)$ were measured by fluid-coupled pressure transducers. A suction line was attached to the cTAL gas outlet, and 95:5\% $\mathrm{O}_{2}: \mathrm{CO}_{2}$ with vaporized isoflurane $(1 \%-3 \%)$ was used as the sweep gas through the gas inlet. Sweep gas flow was adjusted during cTAL use to maintain the arterial carbon dioxide tension between 35 and $45 \mathrm{~mm} \mathrm{Hg}$. A Hoffmann clamp was placed around the cTAL outlet conduit to restrict flow through the device. After cTAL attachment, the clamps on the cTAL inlet and outlet conduits were removed, and the Hoffmann clamp was loosened until $1 \mathrm{~L} / \mathrm{min}$ flow to the cTAL was achieved. This flow was maintained for 10 minutes for equilibration of fluid volumes and any inflammatory response. Flow to the cTAL was then stopped briefly, and up to $500 \mathrm{~mL}$ of hetastarch and $500 \mathrm{~mL}$ of crystalloid were administered to restore CVP back to pre-cTAL values, if required.

Rest and exercise conditions were then simulated using a continuous dobutamine (Hospira Inc, Lake Forest, Ill) infusion of 0 and 5 $\mu \mathrm{g} \cdot \mathrm{kg}^{-1} \cdot \mathrm{min}^{-1}$, respectively. At each dose, a data set was acquired at baseline, with no flow to the device. Thereafter, the clamps were removed from the cTAL and the Rummel tourniquet was tightened to divert $60 \%$, $75 \%$, and $90 \%$ of CO to the cTAL. At each condition, 10 minutes were allowed for equilibration before data were taken. A data set consisted of recording the average values of all blood pressures and flows. In addition, arterial and device inlet and outlet blood samples were taken and assayed for $\mathrm{pH}$, carbon dioxide tension, and oxygen tension using an ABL 725 blood gas analyzer (Radiometer Copenhagen, Copenhagen, Denmark). 


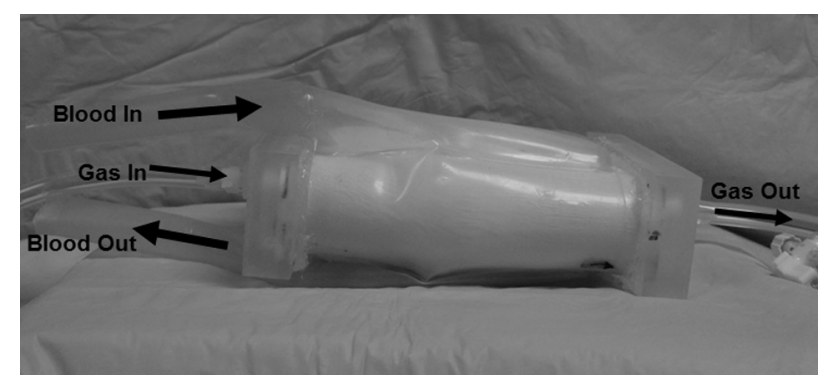

FIGURE 1. The cTAL demonstrating the blood and gas flow paths.

\section{Data Analysis}

Average blood flows and pressures were used to calculate all resistances. The $\mathrm{CO}$ is equal to the average PA flow rate. cTAL resistance, $R_{c T A L}$, was calculated using the following formula:

$$
R_{c T A L}=\frac{P_{\text {in }}-P_{\text {out }}}{Q_{c T A L}}
$$

The pulmonary vascular resistance (PVR) of the native lungs was calculated by the following formula:

$$
P V R=\frac{d P A P-L A P}{C O} .
$$

The resistance of the graft anastomoses, $R_{a}$, was calculated by analyzing all the resistive elements in the experimental pulmonary system setup (Figure 2). Total pulmonary system resistance, $R_{T}$, is defined as the resistance of combined artificial and natural lung system from the proximal PA to the left atrium, and is thus calculated as follows:

$$
R_{T}=\frac{p P A P-L A P}{C O}
$$

Shunt resistance, $R_{s}$, is defined as the resistance of the section of the main PA containing the artificial lung and its anastomoses, which is in series with the natural lungs. It was thus calculated as follows:

$$
R_{s}=R_{T}-P V R
$$

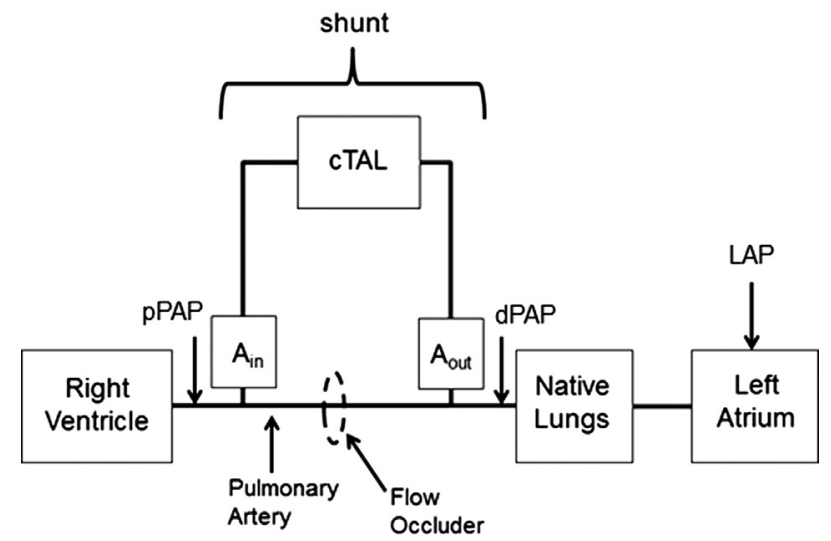

FIGURE 2. Experimental pulmonary system setup with all resistive elements. The shunt includes the anastomoses $\left(A_{\text {in }}\right.$ and $\left.A_{\text {out }}\right)$, the cTAL, and the flow occluder. $c T A L$, Compliant thoracic artificial lung; $p P A P$, proximal pulmonary artery pressure; $A_{\text {in }}$, inlet anastomosis; $A_{\text {out }}$, outlet anastomosis; $d P A P$, distal pulmonary artery pressure; $L A P$, left atrial pressure.
The sum of the anastomoses resistances, $R_{a}$, is assumed to be in series with the cTAL resistance, giving the following relationship:

$$
R_{a}=\frac{R_{s}}{f}-R_{c T A L}
$$

In which $f$ is the fraction of $C O$ diverted to the cTAL. The values of $R_{T}$, $R_{s}$, and $R_{a}$ were thus calculated at each flow condition.

Statistical analyses were performed using the Statistical Package for the Social Sciences version 19 (SPSS, Inc, Chicago, Ill). The analysis of baseline PVR before and after TAL attachment was conducted using a paired 2-tailed Student $t$ test assuming equal variances. To examine whether cTAL resistance varied significantly with flow rate, a 1-way analysis of variance was performed. For comparisons of mean values of all other dependent variables, linear models with correlated error structures (given the repeated measures) were fitted to the observed data. Separate models were fitted for the 0 and $5 \mu \mathrm{g} / \mathrm{kg} / \mathrm{min}$ of dobutamine data. Each model included fixed effects of flow diversion to examine differences between baseline and $60 \%, 75 \%$, and $90 \%$ flow diversion. Alternative covariance structures were compared using information criteria (eg, Akaike information criterion, Bayesian information criterion). In most cases, an autoregressive covariance structure was found to have the best fit. However, Toeplitz and diagonal covariance structures were used for PVR and mean pulmonary artery pressure, respectively. A Bonferroni correction was applied to the contrasts to prevent increases in type I error rates. All data are reported as the mean \pm the standard error.

\section{RESULTS \\ Device Function}

The resistance of the cTAL did not change significantly with flow rate $(P=.16)$, averaging $0.46 \pm 0.02 \mathrm{~mm} \mathrm{Hg} /$ $\left(\mathrm{L} \cdot \mathrm{min}^{-1}\right)$ over the entire range of flows. Because of the relatively high venous saturations $(83.1 \% \pm 1.3 \%)$ and lower hemoglobin $(6.11 \pm 0.17 \mathrm{~g} / \mathrm{dL})$, the gas transfer function of the lung was never challenged. Arterial blood gas hemoglobin oxygen saturations were maintained at $99 \%$ for all of the conditions. Finally, all of the devices functioned without a noticeable decrease in gas exchange or increase in resistance. There was no noticeable clot formation within the device at the conclusion of the experiment.

\section{Sheep Hemodynamics}

During the early equilibration period, there was an event due to blood contact with the artificial lung featuring increased PVR and decreased MAP and CO. This is common to blood-bearing artificial circuits and is normally attributed to inflammation. ${ }^{6}$ During this event, PVR increased from $1.61 \pm 0.32 \mathrm{~mm} \mathrm{Hg} /(\mathrm{L} / \mathrm{min})$ to $3.13 \pm 0.17 \mathrm{~mm} \mathrm{Hg} /(\mathrm{L} /$ $\min )(P=.01)$, CO decreased from $6.58 \pm 0.56 \mathrm{~L} / \mathrm{min}$ to $6.20 \pm 0.53 \mathrm{~L} / \mathrm{min}$, and MAP decreased from $87.6 \pm 6.2$ to $80.9 \pm 3.9$.

Thereafter, $\mathrm{CO}$ was $6.20 \pm 0.53 \mathrm{~L} / \mathrm{min}$ at the experimental baseline and decreased $13 \%$ to $5.40 \pm 0.34 \mathrm{~L} / \mathrm{min}$ at $60 \%$ flow to the cTAL $(P<.01), 25 \%$ to $4.66 \pm 0.31$ $\mathrm{L} / \mathrm{min}$ at $75 \%$ flow to the cTAL $(P<.01)$, and $35 \%$ to $4.05 \pm 0.27 \mathrm{~L} / \mathrm{min}$ at $90 \%$ flow to the cTAL $(P<.01)$ (Figure 3, A). After starting dobutamine at 5 $\mu \mathrm{g} \cdot \mathrm{kg}^{-1} \cdot \mathrm{min}^{-1}$, CO increased to $7.85 \pm 0.70 \mathrm{~L} / \mathrm{min}$ at 

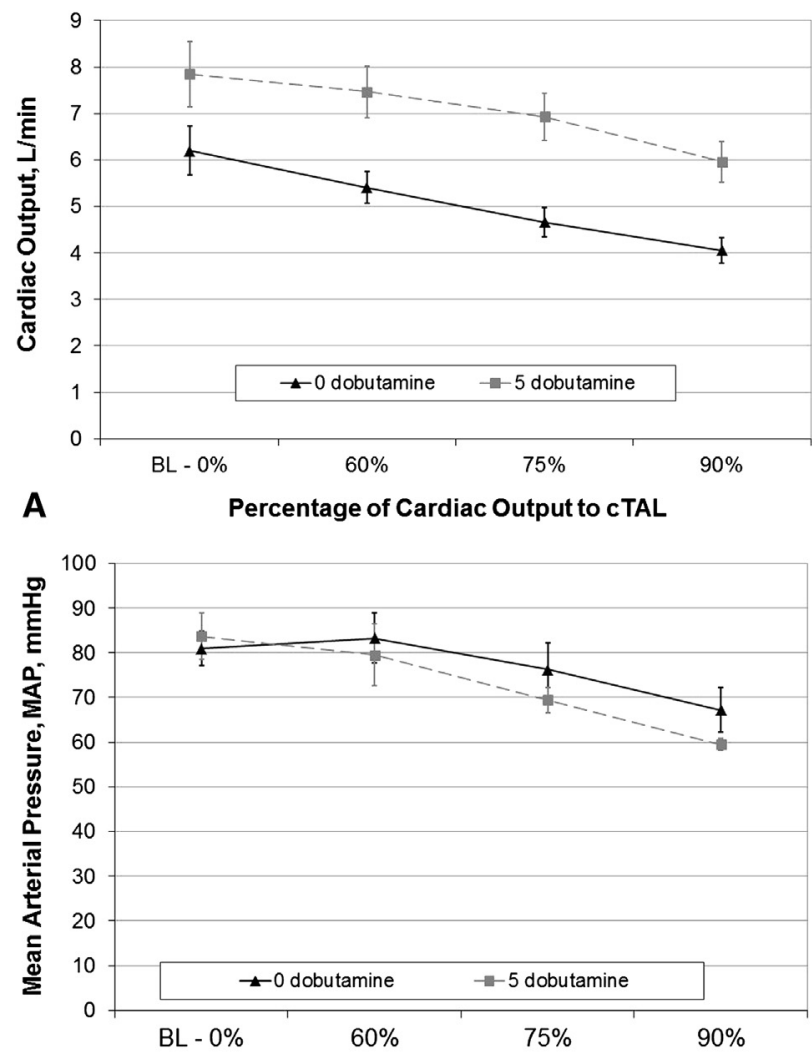

B

Percentage of Cardiac Output to CTAL

FIGURE 3. $\mathrm{CO}(\mathrm{A})$ and MAP (B) versus the percentage of CO shunted to the compliant artificial lung for dobutamine doses of $0 \mu \mathrm{g} / \mathrm{kg} / \mathrm{min}$ and $5 \mu \mathrm{g} /$ $\mathrm{kg} / \mathrm{min}$. $B L$, Baseline; $c T A L$, compliant thoracic artificial lung; $M A P$, mean arterial pressure.

baseline with no flow to the cTAL. Once again, $\mathrm{CO}$ decreased with increasing flows to the cTAL, decreasing 5\% to $7.46 \pm 0.55 \mathrm{~L} / \mathrm{min}(P=.82), 12 \%$ to $6.93 \pm 0.51 \mathrm{~L} /$ $\min (P=.19)$, and $24 \%$ to $5.96 \pm 0.44 \mathrm{~L} / \mathrm{min}(P<.01)$ with $60 \%, 75 \%$, and $90 \%$ of CO going through the cTAL, respectively. Other measures of RV dysfunction varied only slightly and were not as sensitive as CO. The CVP was between 11.4 and $12.5 \mathrm{~mm} \mathrm{Hg}$ under all conditions and did not change significantly with attachment mode at 0 or 5 $\mu \mathrm{g} / \mathrm{kg} / \mathrm{min}$ of dobutamine $(P=.08$ and $P=.59)$. Lactate was within normal ranges for the duration of the experiment (0.8-1.4 mmol/L). The only statistically significant change was a decrease in lactate with increasing flow the cTAL with 0 dobutamine $(P<.01$ vs baseline).

The MAP decreased with increasing flow to the TAL (Figure 3, B), as did CO. The baseline MAP was $81 \pm 4.0$ $\mathrm{mm} \mathrm{Hg}$ and increased slightly to $83 \pm 5.7 \mathrm{~mm} \mathrm{Hg}$ at $60 \%$ of cTAL flow $(P=.99)$ before decreasing to $76 \pm 6.1 \mathrm{~mm} \mathrm{Hg}(P=.88)$ and $67 \pm 5.0 \mathrm{~mm} \mathrm{Hg}$ $(P<.05)$ under $75 \%$ and $90 \%$ cTAL flow conditions, respectively. Under the simulated exercise condition, the

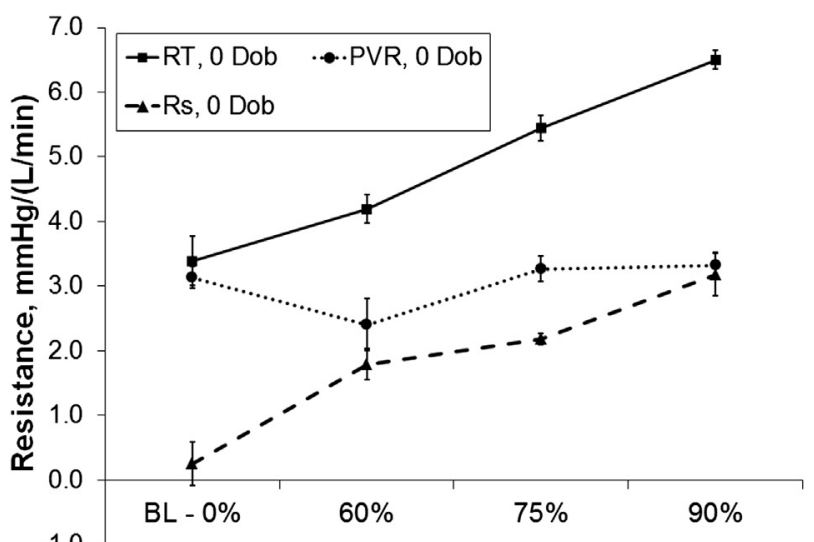

A Percentage of Cardiac Output to CTAL

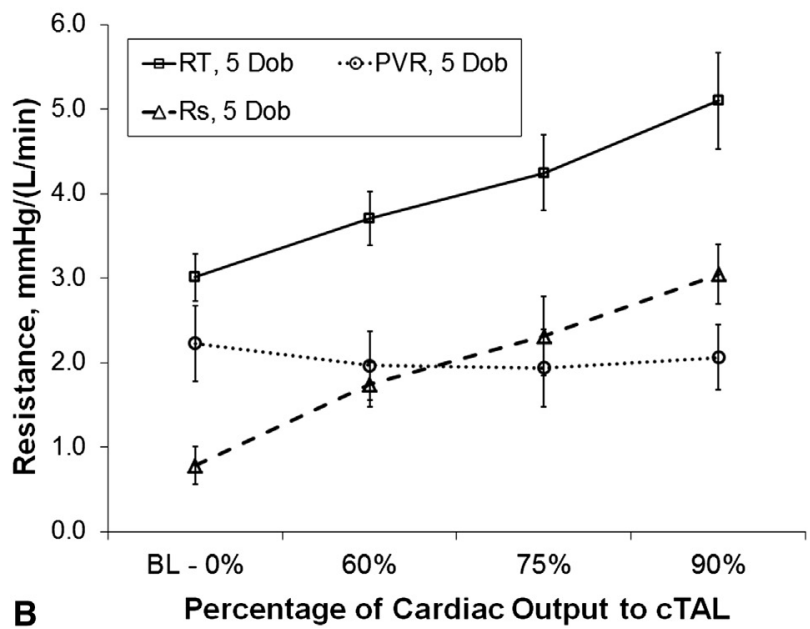

FIGURE 4. Total pulmonary system resistance, PVR, and shunt resistance at varying percentages of $\mathrm{CO}$ diverted to the compliant artificial lung for dobutamine doses of (A) $0 \mu \mathrm{g} / \mathrm{kg} / \mathrm{min}$ and (B) $5 \mu \mathrm{g} / \mathrm{kg} / \mathrm{min}$. $R T$, Total pulmonary system resistance; $R s$, shunt resistance; $D o b$, dobutamine; $P V R$, pulmonary vascular resistance; $B L$, baseline; $c T A L$, compliant thoracic artificial lung.

baseline MAP was $84 \pm 5.3 \mathrm{~mm} \mathrm{Hg}$. This decreased to $80 \pm 6.9 \mathrm{~mm} \mathrm{Hg}$ at $60 \%$ cTAL flow $(P=.99), 69 \pm 2.8$ $\mathrm{mm} \mathrm{Hg}$ at $75 \%$ flow to the cTAL $(P<.05)$, and $60 \pm 1.3$ $\mathrm{mm} \mathrm{Hg}$ at $90 \%$ flow to the cTAL $(P<.01)$.

The cause of diminishing CO and MAP with increasing flow diversion to the cTAL is increasing RV afterload. Figure 4 shows the total pulmonary system resistance $\left(R_{T}\right)$ and its 2 subsections, shunt resistance $\left(R_{s}\right)$ and PVR. As blood flow is diverted to the cTAL, $R_{T}$ increases linearly at both 0 and $5 \mu \mathrm{g} / \mathrm{kg} / \mathrm{min}$ of dobutamine from $3.39 \pm 0.38$ and $3.01 \pm 0.28 \mathrm{~mm} \mathrm{Hg} /(\mathrm{L} / \mathrm{min})$ at baseline to $6.50 \pm 0.14$ and $5.10 \pm 0.57 \mathrm{~mm} \mathrm{Hg} /(\mathrm{L} / \mathrm{min})$ at $90 \%$ flow to the cTAL. The PVR does not change significantly with flow diversion $(P=.21, .99$, and .99 with increasing cTAL flow in the 0 dobutamine conditions and $P=.35$, 


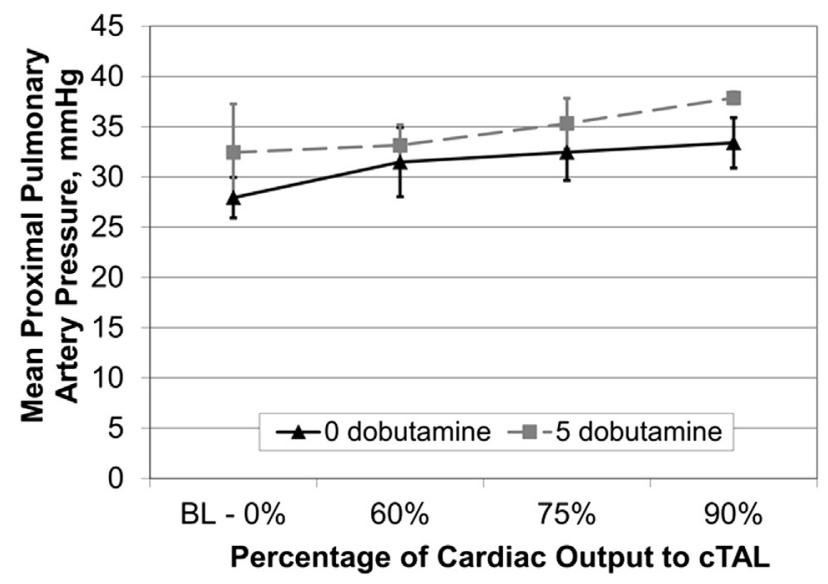

FIGURE 5. Mean pPAP versus the percentage of CO shunted to the compliant artificial lung for dobutamine doses of $0 \mu \mathrm{g} / \mathrm{kg} / \mathrm{min}$ and $5 \mu \mathrm{g} / \mathrm{kg} / \mathrm{min}$. $B L$, Baseline; $c T A L$, compliant thoracic artificial lung.

.59 , and .99 during the $5 \mu \mathrm{g} / \mathrm{kg} / \mathrm{min}$ of dobutamine conditions). However, as the PA is banded, blood flows increasingly through the higher resistance circuit with the TAL and its anastomoses. As a result, $R_{s}$ increases from $0.26 \pm 0.34$ and $0.78 \pm 0.22 \mathrm{~mm} \mathrm{Hg} /(\mathrm{L} / \mathrm{min})$ at baseline to $3.18 \pm 0.32$ and $3.04 \pm 0.35 \mathrm{~mm} \mathrm{Hg} /(\mathrm{L} / \mathrm{min})$ with $90 \%$ of CO going to the TAL with 0 and $5 \mu \mathrm{g} / \mathrm{kg} / \mathrm{min}$, respectively. Finally, the increased resistance was due to increased flow through this high-resistance circuit and not due to changes in the resistances themselves. Neither $R_{C T A L}$ nor $R_{a}$ changed significantly with increasing flow diversion $(P=.42$ and $P=.11$ at $0 \mu \mathrm{g} / \mathrm{kg} / \mathrm{min}$ dobutamine and $P=.42$ and $P=.35$ at $5 \mu \mathrm{g} / \mathrm{kg} / \mathrm{min}$ dobutamine for $R_{c T A L}$ and $R_{a}$, respectively). The $R_{a}$ was $2.63 \pm 0.43$, $2.39 \pm 0.17$, and $3.06 \pm 0.37 \mathrm{~mm} \mathrm{Hg} /(\mathrm{L} / \mathrm{min})$ at $60 \%$, $75 \%$, and $90 \%$ diversion at $0 \mu \mathrm{g} / \mathrm{kg} / \mathrm{min}$ of dobutamine, respectively, and $2.25 \pm 0.54,2.60 \pm 0.63 \mathrm{~mm} \mathrm{Hg} /(\mathrm{L} / \mathrm{min})$, and $2.88 \pm 0.39 \mathrm{~mm} \mathrm{Hg} /(\mathrm{L} / \mathrm{min})$ with $60 \%, 75 \%$, and $90 \%$ diversion at $5 \mu \mathrm{g} / \mathrm{kg} / \mathrm{min}$ of dobutamine, respectively.

Because of offsetting changes in $\mathrm{CO}$ and $R_{T}$, pPAP increased only a small amount with increasing flow diversion (Figure 5). Baseline pPAP was $28 \pm 2.0 \mathrm{~mm} \mathrm{Hg}$ and increased by a statistically insignificant amount $(P=.16)$ to $33 \pm 2.5 \mathrm{~mm} \mathrm{Hg}$ at $90 \%$ flow to the cTAL with $0 \mu \mathrm{g} / \mathrm{kg} /$ min of dobutamine. In a similar fashion, the baseline pPAP of $32 \pm 4.8 \mathrm{~mm} \mathrm{Hg}$ increased insignificantly $(P=.98)$ to $38 \pm 0.6 \mathrm{~mm} \mathrm{Hg}$ at $90 \%$ flow to the cTAL with $5 \mu \mathrm{g} / \mathrm{kg} / \mathrm{min}$ of dobutamine.

\section{DISCUSSION}

Several previous studies have examined TAL use in a PA-PA setting. Lick and colleagues ${ }^{15}$ used an early prototype of the MC3 BioLung in conscious, normal sheep with $100 \%$ flow diversion, resulting in poor heart function, including a $50 \%$ incidence of right heart failure. ${ }^{15}$ In surviving sheep, however, heart function improved over the 7-day study. Thereafter, the BioLung was redesigned to reduce blood-flow impedance. The result was a device with an average blood flow resistance of approximately $1.8 \mathrm{~mm} \mathrm{Hg} /(\mathrm{L} / \mathrm{min})$ under simulated blood flow conditions. ${ }^{16}$ Subsequently, this device was tested in conscious sheep with acute respiratory distress syndrome, again with $100 \%$ diversion. This study demonstrated an approximate $20 \%$ decrease in CO, followed by accommodation and normalization of CO. ${ }^{17}$ Sato and colleagues ${ }^{16}$ tested the MC3 BioLung in anesthetized sheep and found a $25 \%$ decrease in CO with $100 \%$ flow diversion. Perlman and colleagues ${ }^{18}$ also tested an early cTAL prototype in 2 groups of anesthetized pigs with $42 \%$ or $100 \%$ flow diversion. This device had an average blood flow resistance of $1.9 \mathrm{~mm} \mathrm{Hg} /(\mathrm{L} / \mathrm{min})$ under the same conditions as the BioLung. ${ }^{19}$ In this setting, CO decreased by $12 \%$ and $42 \%$, respectively.

The goal of the current study was to determine whether further hemodynamic improvements in PA-PA attachment were possible using newer, ultra-low impedance TALs. In vitro studies of this device indicate that resistance is $0.53 \pm 0.06 \mathrm{~mm} \mathrm{Hg} /(\mathrm{L} / \mathrm{min})$ at blood flows of $4 \mathrm{~L} / \mathrm{min}$, and compliance was $5.21 \pm 0.57 \mathrm{~mL} / \mathrm{mm} \mathrm{Hg}{ }^{1}$ This resistance was less than one third of previously published devices, and the compliance was $18 \%$ greater than previous designs. ${ }^{16,19,20}$ This study confirmed that it is possible to achieve PA-PA attachment with both significant TAL flow and minimal impact on hemodynamics. However, CO decreased $25 \%$ and $12 \%$ during rest and exercise conditions at $75 \%$ diversion. As a result, diversion of $60 \%$ of $\mathrm{CO}$ or less seems to be a more reasonable level. At $60 \%$, there was a $13 \%$ and $8 \%$ decrease in $\mathrm{CO}$ at rest and exercise conditions, respectively. This is a level to which the heart could likely accommodate (see next page).

The CO decrease in the present study is similar to that in the studies by Sato and colleagues ${ }^{16}$ and Perlman and colleagues, ${ }^{18}$ despite lower TAL and pulmonary system resistances. Those studies demonstrated a $4 \mathrm{~mm} \mathrm{Hg} /(\mathrm{L} / \mathrm{min})$ increase in pulmonary system resistance at $100 \%$ flow diversion versus approximately $3.1 \mathrm{~mm} \mathrm{Hg} /(\mathrm{L} / \mathrm{min})$ at $90 \%$ diversion in the current study. A pulmonary system resistance reduction of $0.9 \mathrm{~mm} \mathrm{Hg} /(\mathrm{L} / \mathrm{min})$ should lead to a $5 \%$ to $7 \%$ increase in $\mathrm{CO},{ }^{21,22}$ or only 0.3 to $0.4 \mathrm{~L} / \mathrm{min}$. Thus, the benefits gained from even a large decrease in TAL resistance are small. Ultimately, the largest resistance in the system is not the cTAL itself, but that of the anastomoses. Anastomoses resistances averaged approximately $2.6 \mathrm{~mm} \mathrm{Hg} /(\mathrm{L} / \mathrm{min})$ in the current study, similar to that of previous studies, ${ }^{16,21}$ whereas the cTAL resistance is now only $0.5 \mathrm{~mm} \mathrm{Hg} /(\mathrm{L} / \mathrm{min})$.

Despite the limited improvement in $\mathrm{CO}$, minimization of TAL resistance should remain the goal to minimize RV strain. Three groups have reported on the use of the Novalung 
lung assist device in a PA-LA configuration in 7 patients with marked pulmonary hypertension. ${ }^{8-10}$ Average device flow in these patients ranged from 2.5 to $3.0 \mathrm{~L} / \mathrm{min}$ with a pressure decrease of 25 to $30 \mathrm{~mm} \mathrm{Hg}$ across the device, or a device resistance of $10 \mathrm{~mm} \mathrm{Hg} /(\mathrm{L} / \mathrm{min}) .{ }^{10}$ Although this still allowed modest RV unloading in the PA-LA setting, this device would not be tolerated in a PA-PA configuration.

Despite these limitations, long-term results in conscious subjects should be significantly better. Two previous studies have indicated improved $\mathrm{CO}$ over 3 to 7 days of PA-PA support in conscious sheep with $100 \%$ flow diversion. ${ }^{16,17}$ This may be due to RV accommodation or alleviation of the effects of both anesthesia and any inflammatory response to the device. Prolonged anesthesia leads to a progressive decrease in MAP, RV perfusion, and thus $\mathrm{CO}^{23,24}$ There was also an initial event that increased PVR and most likely a loss in cardiac function before the experimental period beginning. ${ }^{6,23}$ These events are common to blood contact with any blood gas exchanger, be it cardiopulmonary bypass, ECMO, or the cTAL and are typically attributed to inflammation. ${ }^{6}$ This effect typically resolves within 24 hours after initiation of ECMO, ${ }^{25,26}$ and there is no evidence of a significant systemic inflammation within 24 hours after TAL attachment. ${ }^{7}$ Thus, as arterial pressure returns to normal and the inflammation abates, cardiac function is likely to improve in awake sheep.

As stated earlier, the ability of the device to transfer oxygen was never challenged because of the use of $100 \%$ inspired oxygen and low hemoglobin. As a result, device outlet oxygen saturation was always greater than $99 \%$. Gas exchange function for this device has recently been described under more challenging conditions. ${ }^{14}$ In that study, inlet blood conditions were set to those from the Food and Drug Administration "Guidance for Cardiopulmonary Bypass Oxygenators 510(k) Submissions" and the standards provided by American National Standards Institute/Association for the Advancement of Medical Instrumentation/International Organization for Standardization $7199 .^{27,28}$ These were, in part, hemoglobin $=12 \pm 1 \mathrm{~g} / \mathrm{dL}$, oxygen saturation $=65 \% \pm 5 \%$, and carbon dioxide tension $=45 \pm 5$ $\mathrm{mm} \mathrm{Hg}$. With these inlet conditions, outlet oxyhemoglobin saturation was greater than $99 \%$ and partial pressure of oxygen was at least $243 \mathrm{~mm} \mathrm{Hg}$ with up to $7 \mathrm{~L} / \mathrm{min}$ of blood flow. The resulting oxygen transfer at $7 \mathrm{~L} / \mathrm{min}$ was $395 \mathrm{~mL} / \mathrm{min}$. The $\mathrm{CO}_{2}$ transfer was not examined. However, $\mathrm{CO}_{2}$ transfer is typically excessive in these devices, requiring $\mathrm{CO}_{2}$ to be added into the sweep gas. ${ }^{7}$ This level of gas transfer is more than sufficient for this application.

\section{CONCLUSIONS}

The cTAL tested in the current study had a resistance well below previous TALs at all flow rates tested and maintained adequate gas exchange under all conditions.
Despite this, flow diversion to the device should be limited to less than $60 \%$ of $\mathrm{CO}$ in the PA-PA setting to minimize changes in pulmonary hemodynamics. However, further study is required to determine the effect of PA-PA attachment in conscious sheep. Ultimately, if the cTAL can be used in the PA-PA configuration with minimal alteration in hemodynamics, systemic embolic complications could be eliminated.

\section{References}

1. Yusen RD, Shearon TH, Quian Y, Kotloff R, Barr ML, Sweet S, et al. Lung transplantation in the United States, 1999-2008. Am J Transplant. 2010;10:1047-68.

2. Garcia JP, Iacono A, Kon Z, Griffith BP. Ambulatory extracorporeal membrane oxygenation: a new approach for bridge-to-lung transplantation. J Thorac Cardiovasc Surg. 2010;139:e137-9.

3. Mangi AA, Mason DP, Yun JJ, Murthy SC, Pettersson GB. Bridge to lung transplantation using short-term ambulatory extracorporeal membrane oxygenation. J Thorac Cardiovasc Surg. 2010;140:713-5.

4. Nosotti M, Rosso L, Palleschi A, Lissoni A, Crotti S, Marenghi C, et al. Bridge to lung transplantation by venovenous extracorporeal membrane oxygenation: a lesson learned on our first four cases. Transplant Proc. 2010;42:1259-61.

5. Olsson KM, Simon A, Strueber M, Hadem J, Wiesner O, Gottlieb J, et al. Extracorporeal membrane oxygenation in nonintubated patients as bridge to lung transplantation. Am J Transplant. 2010;10:2173-8.

6. Cook KE, Mockros LF. Biocompatibility of artificial lungs. In: Vaslef SN, Anderson RW, eds. The Artificial Lung. Austin, TX: Landes Bioscience; 2002:65-97

7. Sato H, Hall C, Lafayette N, Pohlmann J, Padiyar N, Toomasian JM, et al. Thirtyday in-parallel artificial lung testing in sheep. Ann Thorac Surg. 2007;84: 1136-43.

8. Schmid C, Philipp A, Hilker M, Arlt M, Trabold B, Pfeiffer M, et al. Bridge to lung transplantation through a pulmonary artery to left atrial oxygenator circuit. Ann Thorac Surg. 2008;85:1202-5.

9. Gazit AZ, Sweet SC, Grady RM, Huddleston CB. First experience with a paracorporeal artificial lung in a small child with pulmonary hypertension. J Thorac Cardiovasc Surg. 2011;141:e48-50.

10. Strueber M, Hoeper MM, Fischer S, Cypel M, Warnecke G, Gottlieb J, et al Bridge to thoracic organ transplantation in patients with pulmonary arterial hypertension using a pumpless lung assist device. Am J Transplant. 2009;9: 853-7.

11. Lettieri CJ, Nathan SD, Barnett SD, Ahmad S, Shorr AF. Prevalence and outcomes of pulmonary arterial hypertension in advanced idiopathic pulmonary fibrosis. Chest. 2007;129:746-52.

12. Thabut G, Dauriat G, Stern JB, Logeart D, Lévy A, Marrash-Chahla R, Mal H Pulmonary hemodynamics in advanced COPD candidates for lung volume reduction surgery or lung transplantation. Chest. 2005;127:1531-6.

13. Tonelli AR, Fernandez-Bussy S, Lodhi S, Akindipe OA, Carrie RD, Hamilton K, et al. Prevalence of pulmonary hypertension in end-stage cystic fibrosis and correlation with survival. J Heart Lung Transplant. 2010;29:865-72.

14. Schewe RE, Khanafer KM, Arab A, Mitchell JA, Skoog DJ, Cook KE. Design and in vitro assessment of a compliant thoracic artificial lung. ASAIO J. 2012; 58:583-9.

15. Lick SD, Zwischenberger JB, Alpard SK, Witt SA, Deyo DM, Merz SI. Development of an ambulatory artificial lung in an ovine survival model. ASAIO J. 2001;47:486-91.

16. Sato H, McGillicuddy JW, Griffith GW, Cosnowski AM, Chambers SD, Hirschl RB, et al. Effect of artificial lung compliance on in vivo pulmonary system hemodynamics. ASAIO J. 2006;52:248-56.

17. Zwischenberger JB, Wang D, Lick SD, Deyo DJ, Alpard SK, Chambers SD. The paracorporeal artificial lung improves 5-day outcomes from lethal smoke/burninduced acute respiratory distress syndrome in sheep. Ann Thorac Surg. 2002; 74:1011-6.

18. Perlman CE, Cook KE, Seipelt R, Mavroudis C, Backer CL, Mockros LF. Hemodynamic consequences of artificial lung attachment in an in vivo porcine model. ASAIO J. 2005;51:412-25.

19. Cook KE, Perlman CE, Seipelt R, Backer CL, Mavroudis C, Mockros LF. Hemodynamic and gas transfer properties of a compliant thoracic artificial lung. ASAIO J. 2005;51:404-11. 
20. Schewe RE, Khanafer KM, Orizondo RA, Cook KE. Thoracic artificial lung impedance studies using computational fluid dynamics and in vitro models. Ann Biomed Eng. 2012;40:628-36.

21. Akay B, Foucher JA, Camboni D, Koch KL, Kawatra A, Cook KE. Hemodynamic design requirements for in series thoracic artificial lung attachment in a model of pulmonary hypertension. ASAIO J. 2012;58:426-31.

22. Kim J, Sato H, Griffith JW, Cook KE. Cardiac output during high afterload artificial lung attachment. ASAIO J. 2009;55:73-7.

23. Brooks H, Kirk ES, Vokonas PS, Urschel CW, Sonnenblick EH. Performance of the right ventricle under stress: relation to right coronary flow. J Clin Invest. 1971;50:2176-83.

24. Vlahakes GJ, Turley K, Hoffman JI. The pathophysiology of failure in acute right ventricular hypertension: hemodynamic and biochemical correlations. Circulation. 1981;63:87-95.
25. Plotz FB, van Oeveren W, Bartlett RH, Wildevuur CR. Blood activation during neonatal extracorporeal life support. J Thorac Cardiovasc Surg. 1993;105: 823-32.

26. Fortenberry JD, Bhardwaj V, Niemer P, Cornish JD, Wright JA, Bland L. Neutrophil and cytokine activation with neonatal extracorporeal membrane oxygenation. J Pediatr. 1996;128:670-8.

27. Food and Drug Administration. Guidance for Cardiopulmonary Bypass Oxygenators 510(k) Submissions; Final Guidance for Industry and FDA Staff. 2000. Available at: http://www.fda.gov/MedicalDevices/ DeviceRegulationandGuidance/GuidanceDocuments/ucm073668.htm. Accessed January 21, 2013.

28. Association for the Advancement of Medical Instrumentation. Cardiovascular Implants and Artificial Organs-Blood-Gas Exchangers (Oxygenators). Arlington, VA: Association for the Advancement of Medical Instrumentation; 2009. 